\title{
Is caching the key to exclusion in corvids? The case of carrion crows (Corvus corone corone)
}

\author{
Sandra Mikolasch $\cdot$ Kurt Kotrschal • \\ Christian Schloegl
}

Received: 15 March 2011/Revised: 9 June 2011/Accepted: 24 June 2011/Published online: 13 July 2011

(C) The Author(s) 2011. This article is published with open access at Springerlink.com

\begin{abstract}
Recently, two corvid species, food-caching ravens and non-caching jackdaws, have been tested in an exclusion performance (EP) task. While the ravens chose by exclusion, the jackdaws did not. Thus, foraging behaviour may affect EP abilities. To investigate this possibility, another food-caching corvid species, the carrion crow (Corvus corone corone), was tested in the same exclusion task. We hid food under one of two cups and subsequently lifted either both cups, or the baited or the unbaited cup. The crows were significantly above chance when both cups were lifted or when only the baited cup was lifted. When the empty cup was lifted, we found considerable inter-individual variation, with some birds having a significant preference for the un-baited but manipulated cup. In a follow-up task, we always provided the birds with the full information about the food location, but manipulated in which order they saw the hiding or the removal of food. Interestingly, they strongly preferred the
\end{abstract}

S. Mikolasch · K. Kotrschal · C. Schloegl

Konrad Lorenz Forschungsstelle,

Grünau im Almtal, Austria

S. Mikolasch $(\bowtie) \cdot$ K. Kotrschal · C. Schloegl

Department of Behavioural Biology, University of Vienna,

Althanstraße 14 (UZA I), 1090 Vienna, Austria

e-mail: sandra.mikolasch@klf.ac.at

C. Schloegl

Department of Cognitive Biology, University of Vienna,

Vienna, Austria

Present Address:

C. Schloegl

Cognitive Ethology Lab, German Primate Center, Göttingen and Courant Research Centre "Evolution of Social Behaviour",

University of Göttingen, Göttingen, Germany cup which was manipulated last, even if it did not contain any food. Therefore, we repeated the first experiment but controlled for the movement of the cups. In this case, more crows found the food reliably in the un-baited condition. We conclude that carrion crows are able to choose by exclusion, but local enhancement has a strong influence on their performance and may overshadow potential inferential abilities. However, these findings support the hypothesis that caching might be a key to exclusion in corvids.

Keywords Carrion crow $\cdot$ Exclusion performance $\cdot$ Local enhancement · Two-choice task · Reasoning

\section{Introduction}

Exclusion performance (EP) is defined as 'selecting the correct alternative by logically excluding other potential alternatives' (Call 2006). To test for this ability, a twochoice task is commonly used, in which the animal is confronted with two options, A and B. Then, it is informed that one option, say B, is incorrect (i.e. un-baited). Two possible approaches can lead to the correct choice of A. Either the individual avoids the incorrect option-and therefore, its choice is only based on knowledge about B (Aust et al. 2008) - or it is aware that option A is correct because B is not, i.e., that the food is in cup A because B is empty. The latter mechanism has been labelled 'inference by exclusion' (Call 2004, 2006) or 'reasoning by exclusion' (Erdöhegyi et al. 2007) and is presumably cognitively more demanding than the first one.

Originally, EP has been discussed as a learning mechanism facilitating the acquisition of language in humans (Dixon 1977; Markman and Wachtel 1988), and therefore, many language-trained animals have been tested. Sea lions 
Zalophus californianus (Schustermann and Krieger 1984), bottlenose dolphins Tursiops truncatus (Hermann et al. 1984), dogs Canis familiaris (Kaminski et al. 2004; Pilley and Reid 2011) and an African grey parrot Psittacus erithacus (Pepperberg 2006) had been trained to associate various objects with verbal labels. When confronted with a set of familiar objects and one new object, they matched the new object with a new, unknown label. This suggests that their choice was based on the exclusion of the known objects. Interestingly, they could also memorise and learn the meaning of these new labels through exclusion (Bloom 2004; Fischer et al. 2004; Markman and Abelev 2004).

EP may not be restricted to vocal learning but may also facilitate the performance in forced discrimination tasks. For instance, in a matching-to-sample (MTS) task, animals are trained to match several objects as correct and others as incorrect. Finally, an already known incorrect object is matched with a new object, so that a correct choice of the new object would need to be based on exclusion. In such a task, chimpanzees Pan troglodytes (Beran and Washburn 2002; Tomonaga 1993), sea lions (Kastak and Schustermann 2002), dogs (Aust et al. 2008) and pigeons Columba livia (Aust et al. 2008; Clement and Zentall 2003) were able to match a new object via exclusion; additionally, pigeons also showed EP in a similar non-matching-tosample task (Zentall et al. 1981).

In an influential study, Call (2004) devised a foodfinding task to test for exclusion. This task cannot distinguish unequivocally between exclusion based on true inference about the correct option and exclusion based on the avoidance of the incorrect option (Paukner et al. 2009); still, it provides an easy-to-use tool to compare various species in an ecologically more relevant context than the before-mentioned test designs. In this task, an experimenter hid a food reward in one of two boxes and then provided the subjects with different information by opening either one or both boxes. Hence, when only the content of the un-baited box was shown to the animals, they had to exclude this box and choose the opposite box to find the hidden food. The Great Apes (Call 2004) and several monkeys (capuchin monkeys Cebus apella (Paukner et al. 2006, 2009; Sabbatini and Visalberghi 2008); Tonkean macaques Macaca tonkeana (Petit et al. 2005) and baboons Papio hamadryas anubis (Schmitt and Fischer 2009)) showed strong evidence for the ability to choose by exclusion, whereas dogs (Bräuer et al. 2006; Erdöhegyi et al. 2007) are only able to do so under very specific circumstances.

Taken together, a diverse range of species demonstrated EP in very different experiments, but it is not clear if they show EP in certain contexts only or if they can apply this ability broadly across various contexts (Schloegl et al. 2009a). The first case would be in line with the 'adaptive specialisation hypothesis', which aims to explain the evolution of intelligence in general and suggests that each species evolved specific cognitive abilities in adaptation to their socio-ecology (de Kort and Clayton 2006; Kamil 1987); the second case would support the 'general process view', which proposes a wider set of cognitive abilities as a consequence of the evolution of large brains (Bolhuis and Macphail 2001).

When Schloegl et al. (2009b) conducted the abovementioned food-finding task in birds, they found that ravens Corvus corax, but not keas, Nestor notabilis, were able to choose by exclusion. One might speculate that this finding represents a cognitive difference between two distantly related taxa (Hackett et al. 2008), but both groups are commonly assumed to possess advanced levels of cognitive abilities (Emery 2006). Alternatively, ecological differences may explain the differences between the two species, as ravens cache food and pilfer the caches of others (Heinrich 1989), whereas keas do not cache at all. It had been suggested that feeding ecology could affect the prevalence of EP in corvids (Schloegl et al. 2009b), as cachers are frequently confronted with pilfering and consequently empty cache sites; thus, the sight of an empty food location may inform a cacher about the fate of food that had been present before, whereas the same may not be true for a non-caching species. This argument is supported not only by the finding that non-caching jackdaws Corvus monedula fail to show EP in the same test paradigm in which ravens had been successful (Schloegl 2011), but also from another, unrelated foraging task in which jackdaws used information about the absence of food differently than related, food-caching jays (GouldBeierle 2000).

Thus, the currently available data support the adaptive specialisation hypothesis to explain the prevalence of EP in corvids, but further studies on more species are clearly needed, as only one caching species has been tested so far. Carrion crows (Corvus corone corone) are closely related to ravens, possess a similar social organisation and do cache food, although a bit more seasonal than ravens (dos Anjos et al. 2009; Goodwin 1986). Therefore, this species is an ideal candidate for further studies and similar test setups to that used in ravens and jackdaws seem to be feasible. We here conducted a series of experiments to test the exclusion abilities of carrion crows. First, we replicated the previous studies of Schloegl and co-workers; this was followed by two follow-up experiments, in which we aimed to test and to control for the effect of local enhancement, as this had been shown to mask exclusion abilities in dogs (Erdöhegyi et al. 2007). We predicted that the crows would perform similar to ravens and choose by exclusion if caching may indeed be linked to EP in corvids. 


\section{Experiment 1: cup lifting}

Methods

\section{Subjects}

Seven hand-raised carrion crows (four males, three females, aged 0.5-20 years), which were individually marked, participated in this study. They were housed in outdoor aviaries at the Konrad Lorenz Research Station in Grünau im Almtal, Austria. Two crows lived together as a pair in an aviary of approximately $14 \mathrm{~m}^{2}$ with a height of $2.5 \mathrm{~m}$ and the other five lived together with two not tested individuals in an aviary of approximately $47 \mathrm{~m}^{2}$ with an average height of $3 \mathrm{~m}$. Both aviaries had natural vegetation like small bushes, grass and stones. Additionally, perches were affixed and naturally occurring obstacles and wooden walls provided hiding places. For testing, the crows were separated individually in one compartment of the aviary (12 and $10 \mathrm{~m}^{2}$, respectively), which was open to all crows when not being tested. Although the test compartment was not visually isolated, none of the subjects was observed by other birds when being tested. The birds were fed once in the morning and tested in the late afternoon.

\section{Material}

A wooden platform $(30 \mathrm{~cm} \times 40 \mathrm{~cm})$ was attached to the aviary's outer wire mesh boundary in a height of $35 \mathrm{~cm}$ above ground; adjacent to it, another wooden platform $(50 \mathrm{~cm} \times 45 \mathrm{~cm})$ was attached on the inner wire mesh boundary at the same height, on which the birds were able to sit during testing. Two identical plastic cups $(6.5 \mathrm{~cm}$ in diameter and $7.5 \mathrm{~cm}$ in height) and a plastic platform $(35 \mathrm{~cm} \times 10 \mathrm{~cm})$, which was free to move on the wooden platform, were used to present the set-up (see Fig. 1). The reward was a piece of dried dog food, which is preferred by the crows but not available during normal feeding.

\section{Procedure and design}

All experiments were conducted between May and September 2009. The crows were habituated to the apparatus before testing to avoid neophobic reactions during training and testing.

Prior to testing, all crows received a training phase to ensure that they reliably choose the baited cup when having seen were the reward was hidden. Here, the plastic platform was positioned on the outer wooden platform, approximately $10 \mathrm{~cm}$ away from the wire mesh. The experimenter (E; S.M.) visibly placed a reward on it and then simultaneously positioned the two cups on the platform in approximately $20 \mathrm{~cm}$ distance from each other,

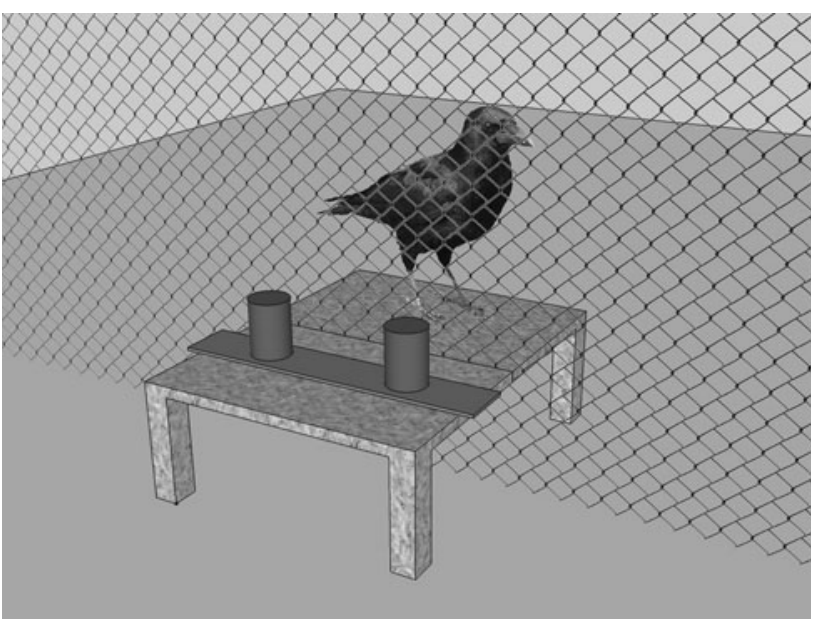

Fig. 1 Basic test set-up for all three experiments

with one cup covering the reward. The plastic platform was pushed to the wire mesh to allow the crow to make a choice by touching a cup with its beak. The chosen cup was lifted by $\mathrm{E}$, and the crow was allowed to take the reward by itself or to see the empty cup. The position of the reward (left/ right) was semi-randomized, with the food on the same side for not more than two consecutive trials. The next trial started after 10-20 s when E had prepared the cups again. The crows received daily sessions consisting of ten trials each. They had to choose the baited cup in at least eight out of ten trials in two consecutive sessions to advance to the test phase.

In the test phase, the reward was hidden underneath one of the two cups below the wooden platform and out of view of the birds. The food was positioned randomly on the left or on the right, with the exception that it was not placed on the same side in more than two consecutive trials. The plastic platform with the two cups was then placed on the wooden platform in view but out of reach of the birds, approximately $10 \mathrm{~cm}$ away from the wire mesh. Then, one of the following conditions was conducted:

Both $\mathrm{E}$ touched both cups with her hands simultaneously, lifted them to a height of approximately $20 \mathrm{~cm}$ above the platform and then returned the cups to the starting position.

Baited $E$ touched both cups but lifted the baited cup only so that the food could be seen on the platform. During the presentation, E continued to touch the un-baited cup. Un-baited As before, but now the empty cup was lifted. Control No cup was lifted, but both cups were touched by $\mathrm{E}$.

Each cue lasted for $5 \mathrm{~s}$, and $\mathrm{E}$ looked straight ahead throughout the trial to avoid unintentional cueing. Then, $\mathrm{E}$ pushed forward the plastic platform towards the wire mesh 
to allow the crow to make a choice; if it chose correctly, it received the reward; if it chose incorrectly, the empty cup was lifted. Following this procedure, E removed the plastic platform and the two cups from the wooden board without lifting the non-chosen cup, and the next trial began. The crows received 12 sessions, with 8 trials per session, consisting of 2 trials of each condition in randomized order.

\section{Data analysis}

All sessions were videotaped and later analysed from tape. Per trial, we measured whether the bird chose the baited or the un-baited cup. As the choice of a cup was unambiguous in any case, we did not calculate an inter-observer reliability. If the data were not normally distributed, we applied non-parametric statistics. We tested for differences in percentage of correct choices between the conditions using a Friedman test. For post hoc analysis, we used the Student-Newman-Keuls (SNK) method. The performance in the first half and in the second half of the experiment was compared using paired $t$ tests or Wilcoxon tests, as appropriate. To assess whether the birds' success rates differed from chance, we used a Binomial test. All tests were conducted two-tailed, and alpha was set to 0.05 . Data analysis was conducted using Sigma Plot 11.0 and SPSS 11.5 for Windows.

\section{Results}

The crows received $40.0 \pm 19.3$ ( $\bar{x} \pm \mathrm{SD}$; range: $20-65)$ training trials until they reached the criterion. In the test phase, the birds' performance differed between the conditions (Friedman: $N=7, \chi^{2}=17.294, d f=3, P<0.001$ ). Post hoc analyses revealed no significant difference between the both and the baited condition (SNK: both vs. baited: $P>0.05$; Fig. 2), but the birds were significantly better in these two conditions than in the control and in the un-baited condition (SNK: all comparisons: $P<0.05$; Fig. 2). In contrast, the control condition and the un-baited condition did not differ significantly from each other (SNK: un-baited vs. control: $P>0.05$; Fig. 2). There was no significant improvement or decline over the course of the experiment in any condition (both: Wilcoxon: $N=7$, $\mathrm{T}^{+}=3.0, P=1.0$; all other comparisons: paired $t$ test: $P \geq 0.172$ ).

On an individual level, all birds selected the baited cup on the majority of the trials in the baited and in the both condition, with six of seven birds being significant in the both condition (Binomial test: for these six birds, all $P<0.023$, the seventh bird, $P=0.152$ ); all birds significantly preferred the baited cup in the baited condition (Binomial test: all $P<0.002)$. In the un-baited condition, one bird significantly preferred the baited cup (Binomial test: $P=0.002$ ),

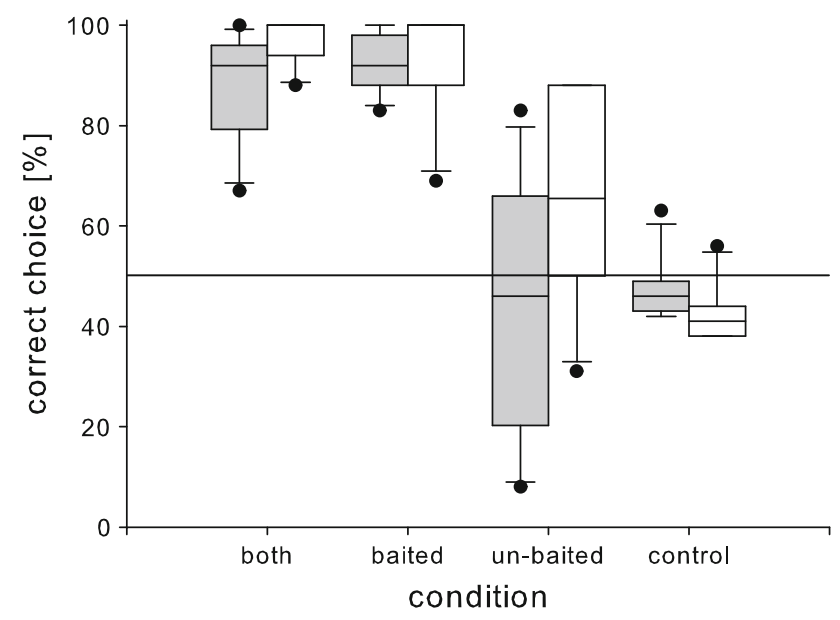

Fig. 2 Percentage of correct choices in experiment 1 and 3. The grey bars show the performance of the crows in experiment 1 and the white bars show their performance in experiment 3 . The horizontal line indicates the chance level. The box plot shows the median and quartile. The whiskers represent $10 \%$ and $90 \%$ range, dots indicate 5 and $95 \%$ range

whereas two crows had a significant preference for the unbaited cup (Binomial test: both birds: $P<0.001$ ). The other four birds were on chance level (Binomial test: all $P>0.152)$. In the control condition, all birds were on chance level (Binomial test: all $P>0.307$; Table 1).

\section{Discussion}

When the birds saw the food underneath one of the cups in the both and in the baited condition, nearly all of them performed above chance level. When only the un-baited cup was lifted, however, only one bird chose the baited cup significantly above chance. Thus, against our predictions, the crows performed worse than the ravens. While four birds performed at chance in the un-baited condition, the two remaining birds had a significant preference for the manipulated, but un-baited cup. However, we found no improvement or decline over the course of the experiment. A similar preference for the lifted, but un-baited cup was found in dogs (Erdöhegyi et al. 2007). Apparently, local enhancement through the movement of a cup was a more salient cue for the dogs than the sight of the empty cup. The influence of human social cues or local enhancement on animals' performances in choice tasks is well known. Apart from dogs, gorillas Gorilla gorilla (Peignot and Anderson 1999), chimpanzees (Itakura et al. 1999), wolves Canis lupus (Viranyi et al. 2008), horses Equus caballus (Krueger et al. 2010) and goats Capra hircus (Kaminski et al. 2005) and at least two bird species, ravens (Schloegl et al. 2008a) and clark's nutcrackers Nucifraga columbiana (TornickTornick et al. 2010), use touch cues or local enhancement to find hidden food in object-choice tasks. 
Table 1 Individual performances of the crows in experiment 1 and 3, given in percentage correct choices. Significant performances (according to a Binomial test) are highlighted in bold

\begin{tabular}{|c|c|c|c|c|c|c|c|c|}
\hline \multirow[t]{2}{*}{ Individual } & \multicolumn{2}{|l|}{ Both } & \multicolumn{2}{|l|}{ Baited } & \multicolumn{2}{|c|}{ Un-baited } & \multicolumn{2}{|c|}{ Control } \\
\hline & Test 1 & Test 3 & Test 1 & Test 3 & Test 1 & Test 3 & Test 1 & Test 3 \\
\hline Baerchen & 95.8 & 100.0 & 91.7 & 100.0 & 83.3 & 87.5 & 62.5 & 56.3 \\
\hline Peter & 66.7 & 100.0 & 91.7 & 87.5 & 62.5 & 50.0 & 45.8 & 37.5 \\
\hline Hugo & 91.7 & 93.8 & 87.5 & 100.0 & 45.8 & 31.3 & 45.8 & 43.8 \\
\hline Gabi & 75.0 & 87.5 & 83.3 & 68.8 & 41.7 & 56.3 & 50.0 & 37.5 \\
\hline Klaus & 100.0 & 100.0 & 100.0 & 100.0 & 12.5 & 75.0 & 45.8 & 37.5 \\
\hline Toeffel & 95.8 & 100.0 & 100.0 & 100.0 & 8.3 & 87.5 & 41.7 & 43.8 \\
\hline Mate & 91.7 & - & 87.5 & - & 66.7 & - & 41.7 & - \\
\hline
\end{tabular}

The question arising is whether the susceptibility to enhancement in our experiment is a result of the complexity of the EP task and the presumed advanced cognitive abilities required to solve it, or whether enhancement in general has such an impact on carrion crows. To answer this question, we ran a second experiment in which a reward was placed visibly under both cups and then different manipulations were performed in full view of the birds. Here, the reward was shown to them again and then either lay back under the cup or taken away. Additionally, a combination of both manipulations was performed with one of the rewards shown to the bird and the other reward taken away or vice versa. We predict that under these circumstances, in which always the full information about the food location is provided, the birds would be less distracted by local enhancement and would be able to choose the baited cup in all conditions.

\section{Experiment 2: object manipulation}

Methods

Subjects

The seven birds from experiment 1 participated in this test.

\section{Material}

The same set-up as in experiment 1 was used.

\section{Procedure}

This test was conducted in direct succession of the first experiment and without further training trials. Now, two rewards were placed on the board visibly and were then covered with the cups. Thus, both cups were now baited. Then, one of the following manipulations was performed in full view of the birds:
Show (S) With one hand E lifted one of the cups to a height of approximately $20 \mathrm{~cm}$ and with the other hand she took the reward between her fingertips and clearly showed it to the bird. After this, she laid the reward back on the same position as before and covered it with the cup.

Take (T) As above, with the exception that the reward was taken away and put in E's pocket after having been shown to the bird.

Show and Take (ST) Now, both cups were lifted sequentially. The reward underneath the first cup was shown to the bird (identical to 'Show' manipulation), and the reward underneath the second cup was lifted and put in E's pocket (identical to 'Take' manipulation).

Take and Show (TS) As above, but the two manipulations were conducted in reversed order.

Each manipulation was performed slowly (approximately $5 \mathrm{~s}$ ), and $\mathrm{E}$ assured that the bird watched the whole time. Then, the plastic platform was pushed forward and the bird was allowed to make a choice. After the bird had made its choice, the plastic platform and the cups remained on the board and a possibly remaining reward was removed in full view of the bird. The crows received nine sessions, with eight trials per session, consisting of two trials of each condition in randomized order. The cup (left or right) and the order of manipulations (left or right first) were randomly manipulated.

Note that in the condition S, both cups were baited, but we were interested in how often the birds would choose the cup that had been manipulated. Therefore, in the $\mathrm{S}$ condition, we scored whether the birds chose the manipulated cup, whereas in the other conditions we scored if they chose the baited cup.

\section{Data analysis}

The birds' choice was defined in the same way as in the first experiment. As the data were normally distributed, we 

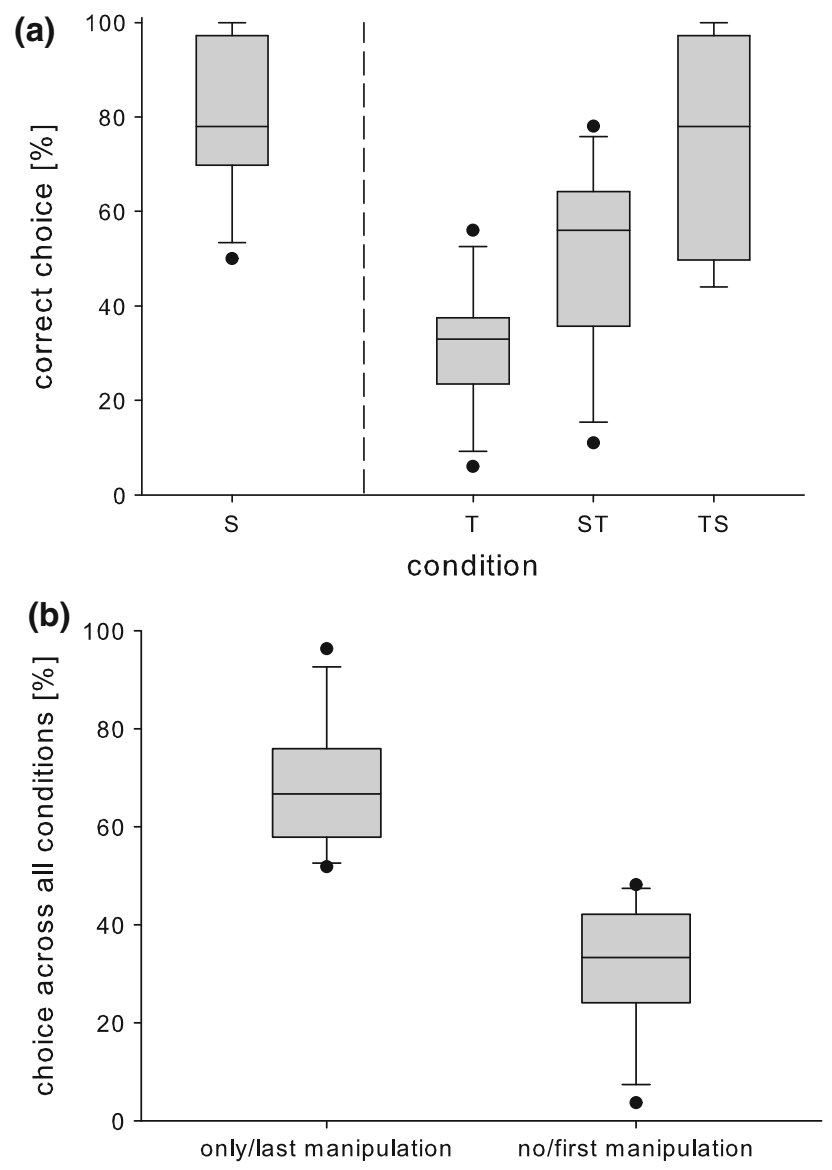

Fig. 3 Preference for the manipulated cup in experiment 2. a Percentage of correct choices in the four conditions of experiment 2 . In the $S$ condition, we plotted the choice of the manipulated cup (note that the choice of both cups would have been correct), whereas in the other conditions we plotted the choice of the baited cup. b Percentage of choices of the only or last manipulated cup and for the not or the first manipulated cup across all four conditions. The box plots show the median and quartile. The whiskers represent 10 and $90 \%$ range, dots indicate 5 and $95 \%$ range

used a one-way repeated measures ANOVA to test for differences between conditions. For post hoc analysis, we used the Student-Newman-Keuls (SNK) method. To look for preferences for the manipulation of the cups, we used a paired $t$ test.

\section{Results}

The performance of the birds differed between conditions (one-way repeated measures ANOVA: $F_{6,27}=8.379$, $P=0.001$; Fig. 3a). In condition $\mathrm{S}$, where the food was shown again, the birds most frequently chose the manipulated cup, even though both cups contained food. In condition $\mathrm{T}$, the birds again preferentially chose the manipulated cup, even though it did not contain food. Consequently, they obtained food significantly more often in condition $\mathrm{S}$ than in condition $\mathrm{T}(\mathrm{SNK}: P<0.05)$. Similarly, they preferred the cup that was manipulated last when two manipulations were performed, even when they had seen the food being removed from underneath the second cup. This resulted in the birds choosing the baited cup significantly more often in the TS condition than in the ST condition (SNK: $P<0.05)$. Consequently, as the last manipulation appeared to be crucial, no significant difference was found between condition $S$ and TS (SNK: $P>0.05$ ) and between T and ST (SNK: $P>0.05$ ). Furthermore, the birds' performance was significantly better in the $\mathrm{S}$ condition than in the ST condition (SNK: $P<0.05)$ and significantly worse in the $\mathrm{T}$ than in the $\mathrm{TS}$ condition (SNK: $P<0.05$ ).

When combining the data of all four conditions, the crows chose the last (or only) handled cup significantly more often than the first (or untouched) cup (paired $t$ test: $N=7, t=3.395, d f=6, P=0.015$; Fig. 3b).

\section{Discussion}

In contrast to our predictions, the birds did not choose the baited cup reliably in all conditions. They were highly affected by the manipulation through the experimenter and preferred the last (or only) handled cup even if the food had been removed from there. This preference for the ultimate object manipulated in a sequence of manipulations is known as recency effect (Pineno and Miller 2005) and has been found, among others, in monkeys (Wright et al. 1985), pigeons (Wright et al. 1985) as well as humans (Knoedler 1999). Although experiment 2 was easier to solve than the previous experiment, as the location of the food was never concealed, the impulse to choose the last manipulated cup was stronger than the knowledge about the food location itself. Interestingly, all individuals were equally affected and not only those two individuals who had shown a strong effect of local enhancement in experiment 1 .

Since enhancement had such a strong effect in experiment 2, we suggest that enhancement cues may have prevented the birds from choosing by exclusion in the first experiment, i.e., in experiment 1 , the birds may have experienced a conflict between making a choice according to the observed action (enhancement) or the observed absence of the food (exclusion); such a masking effect has been described previously for dogs in a very similar experiment (Erdöhegyi et al. 2007). These authors tried to control for the movement of the cups in a follow-up experiment, in which they positioned a smaller, opaque cup covering the food underneath one of the cups. Thereby, both external cups could be lifted while the food remained hidden. In this case, the dogs chose the correct cup when they had the choice between nothing (underneath the empty 
cup) and the internal cup (with the food underneath). However, this set-up does not exclude that the dogs may have chosen the cup itself (i.e. as a toy) rather than because it contained the food. Also, jackdaws showed a strong susceptibility to local enhancement in a similar set-up; to control for a possible preference for the cup (as in the study on dogs), here, two internal cups (one transparent, one opaque) were used (Schloegl 2011). Therefore, in our next experiment, we replicated this experiment to control for the movement of the cups. In detail, two additional smaller cups, transparent and opaque, were used underneath the normal cups. Then, always both external cups were lifted and the amount of information available in each condition was constructed through the combination (opaque or transparent) of the smaller cups. We predicted that the crows should base their choice on exclusion, if their failure in experiment 1 had indeed been due to a masking effect.

\section{Experiment 3: cup lifting with inner cups}

Methods

\section{Subjects}

Six out of seven birds from experiment 1 and 2 participated in this task. One bird, Mate, refused to complete this task and was therefore excluded from the analyses.

\section{Material}

The birds were tested in the same test compartment and with the same test platform as in experiment 1 and 2 . In addition to the two cups from experiment 1 (external cups), four smaller plastic cups $(4 \mathrm{~cm}$ in diameter and $4 \mathrm{~cm}$ in height), two of them laminated with dark tape to make them opaque, were used in this test.

\section{Procedure}

The third experiment was conducted in direct succession of experiment 2 again without any further training trials. The procedure was the same as in the first experiment with the exception that under the external cups always two smaller cups were placed and that both external cups were lifted (and returned to the board) in each condition. The information about the food location was given to the bird through the combination of the smaller cups used in each condition. According to experiment 1, conditions were performed as follows:

Both Two small transparent cups were used with a reward placed under one of them.
Baited A small transparent and a small opaque cup were used, with a reward placed under the transparent cup. Un-baited As before, but with the exception that the reward was hidden underneath the small opaque cup.

Control Two small opaque cups were used with a reward hidden underneath one of them.

The crows received eight sessions with eight trials per session, consisting of two trials of each condition in randomized order; we reduced the number of trials per condition because we were interested in a spontaneous change in choice behaviour.

\section{Data analysis}

The birds' choice was defined in the same way as in the previous experiments. To test for differences between conditions, we used a one-way repeated measures ANOVA. For post hoc analysis, we used the Student-Newman-Keuls (SNK) method. To compare the performances in experiments 1 and 3, we used a two-way repeated measures ANOVA (excluding the subject that participated in experiment 1 only) and Holm-Sidak tests (HS) for post hoc analyses.

\section{Results}

The performance differed between the conditions (one-way repeated measures ANOVA: $F_{5,23}=28.529 ; P<0.001$ ). Post hoc analyses showed that as in experiment 1 , the birds chose the baited cup significantly more often in the both and in the baited condition than in the control condition (SNK: both vs. control: $P<0.05$; baited vs. control: $P<0.05$ ). Importantly and in contrast to experiment 1 , the birds also selected the correct cup significantly more often in the un-baited condition than in the control condition (SNK: un-baited vs. control: $P<0.05$; Fig. 2). We found no significant difference between the both and the baited condition (SNK: both vs. baited: $P>0.05$ ), but the birds were more successful in the baited and in the both condition than in the un-baited condition (SNK: both vs. unbaited: $P<0.05$; baited vs. un-baited: $P<0.05$ ). Overall, there was no change detectable in the birds' performance over the course of the experiment in any condition (comparison of first and second half of the experiment: both and baited condition: Wilcoxon: $P=0.371$; un-baited and control: paired $t$ test: $P \geq 0.638$ ).

On an individual level, all crows had a significant preference for the baited cup in the both condition (Binomial test: $P<0.004$ ) and five out of six birds had this preference also in the baited condition (Binomial test: for these five birds, all $P<0.004$; the sixth bird, $P=0.210$ ). The crow with a significant preference for the baited cup in 
the un-baited condition in experiment $1 \mathrm{kept}$ its preference in experiment 3 (Binomial test: $P=0.004$ ). Those two crows with a significant preference for the un-baited cup in the un-baited condition of experiment 1 now switched to a preference for the baited cup (Binomial test: $P=0.004$ and $P=0.077$, respectively), whereas those crows that where on chance level in experiment 1 continued to do so in experiment 3 (Binomial test: $P>0.210$ ). All crows performed on chance level in the control condition (Binomial test: all: $P>0.454$; Table 1).

To compare the performance of the birds between experiment 1 and 3, a two-way repeated measures ANOVA was conducted. A significant difference between the conditions $\left(F_{5,47}=45.447 ; P<0.001\right)$, but neither between experiment 1 and $3\left(F_{5,47}=3.154, P=0.136\right)$ nor an interaction of both factors $\left(F_{5,47}=1.747, P=0.200\right)$, could be found. Post hoc analyses (Holm-Sidak tests) revealed similar results as found in experiment 1 , with no significant difference between the both and the baited condition (HS: both vs. baited: $P=0.950 ;$ Fig. 2 ), but these two conditions differed significantly from the control and the unbaited condition (HS: both vs. control: $P<0.001$; both vs. un-baited: $P<0.001$; baited vs. control: $P<0.001$; baited vs. un-baited: $P<0.001$; Fig. 2). In contrast, the control condition and the un-baited condition did not differ significantly (HS: un-baited vs. control: $P>0.163$; Fig. 2).

\section{Discussion}

In this third experiment, the birds again performed at a high level in the both and in the baited condition. Although we found no significant difference between experiment 1 and 3 , the birds' performance in the un-baited condition increased. This is mostly due to the improvement of those two birds that had been influenced the most by local enhancement in the first experiment. Now, these two birds chose the baited cup when the food was hidden underneath the opaque cup and only the empty transparent cup was visible. Additionally, we could show that the improvement in the un-baited condition was most likely not influenced by learning, as we could not find a change between the first and the second half of the experiment. Though, it seems as if local enhancement had overshadowed the crows' ability to choose by exclusion in experiment 1 . In comparison to the ravens, the carrion crows showed a similar ability to choose by exclusion, but seemed to be more sensitive to local enhancement.

\section{General discussion}

We here show that similar to ravens, jackdaws and keas, also carrion crows easily find hidden food in a two-choice task if they had seen it before they made their choice (Schloegl 2011; Schloegl et al. 2009b). When only the information about the empty cup was provided and subjects would have to choose by exclusion, only one bird went for the baited cup spontaneously. This is in contrast to our findings in ravens (Schloegl et al. 2009b) and in contrast to our predictions. However, two other birds showed a preference for the lifted, un-baited cup; when we controlled for the movement of the cups in experiment 3 , they reversed their preference and chose the correct, baited cup. This allowed the birds as a group to be successful in the unbaited condition of experiment 3. Such a reversal was not found in a previous study in jackdaws (Schloegl 2011); this indicates that jackdaws and carrion crows were both distracted by the manipulations, but that exclusion abilities were masked in crows only. While absence of evidence should not be mistaken for evidence of absence, it is nevertheless striking that the jackdaws did not solve the identical tasks that ravens and crows mastered. At the very least, this suggests that jackdaws-if capable of exclusion-rely less on this ability than the other two, closely related, species.

Surprisingly, the strong enhancement effect was even more pronounced in experiment 2 , in which most birds were unable to inhibit their impulse to choose the cup handled last or only, even if they had seen that nothing was underneath. This strong effect of the manipulation of the cups in experiment 2 is most likely to be explained by local enhancement or an associative strategy; instead of associating a cup with the presence or the absence of food, they may have associated the number of presentations of food with a cup. For instance, in the $\mathrm{T}$ condition, the food was seen once underneath the correct cup, whereas it was seen twice (at first presentation and at removal) at the incorrect cup (Russel and Thompson 2003). However, while this may explain the performance in the $\mathrm{S}$ and the $\mathrm{T}$ condition, it fails to explain the performance in the ST and TS conditions.

Interestingly, the ravens' susceptibility to the manipulation of the cups was less strong than that of the crows (Schloegl et al. 2009b), which may be due to their prior experimental experience. For the crows, the experiments described here were the first in which they were directly tested by an experimenter in a two-choice task. In contrast, the ravens have participated in a number of such choice tasks (Schloegl et al. 2008a, b) and were therefore more experienced than the crows. For African grey parrots Psittacus erithacus, it is known that the experimental history of an individual could affect its performance in a subsequent experiment (Pepperberg 2007). Thus, different experimental histories of crows and ravens may have resulted in a stronger effect of the cup manipulation in the crows than in the ravens. 
Until recently, inference was believed to be the mechanism underlying the ability to choose by exclusion. However, Paukner et al. (2009) and Schmitt and Fischer (2009) showed that other explanations are feasible. While it is indeed possible that animals have a mental representation of the food underneath the baited cup, they could also use a lower level cognitive function by simply avoiding the empty cup without knowing anything about the other cup. We cannot resolve which mechanisms the crows relied on to solve the task, but the high susceptible to low-level enhancement effects suggests that the birds may have been guided by low-level perceptual mechanisms, thus making avoidance the most likely explanation for the successful solution of the task. Furthermore, although we did not find a significant learning effect in the un-baited condition, it was notable that most of the errors occurred in the first half of the experiments. Thus, we cannot exclude a rapidly learned avoidance of the empty cup.

Nevertheless, we can clearly demonstrate that carrion crows are capable of EP and even though their performance was somewhat weaker than those of ravens and more strongly influenced by local enhancement, they performed better than the keas and jackdaws. Taking all these findings in consideration (Schloegl et al. 2009b; Schloegl 2011), our results are in line with the 'adaptive specialisation hypothesis' (de Kort and Clayton 2006; Kamil 1987), suggesting that different feeding ecologies may have shaped the different performances in the EP task. In contrast to jackdaws and keas, ravens and crows are regularly faced with social interactions related to caching including pilfering and recaching (Bugnyar and Kotrschal 2002). This could also have led to an increased motivational and attentional state during food-finding experiments. Similarly, it has been proposed that caching and non-caching species may value and interpret information about the absence of food differently and non-cachers may be more inclined to return to empty cache sites to see if the food had been replenished (Gould-Beierle 2000). Thus, it appears likely that feeding ecology plays an important role for the ability to choose by exclusion and more precisely, caching might be a key for EP in corvids.

However, another possible explanation for EP in crows is the close phylogenetic relationship to ravens. Exclusion abilities may have emerged in corvids first after the split of the ancestor of present-day jackdaws from the ancestor of present-day ravens and crows. To shed light on this issue, future studies need to investigate EP in other caching corvid species that are more distantly related to crows and ravens and, in particular, of the only other non-caching species beside jackdaws, the white-throated magpie-jay Calocitta formosa (de Kort and Clayton 2006). Furthermore, future studies may incorporate additional parrot species to elucidate whether the performance of keas is representative for parrots.
We should keep in mind that apart from food-caching corvids, also some non-caching mammals like chimpanzees (Call 2004), dolphins (Hermann et al. 1984) and sea lions (Kastak and Schustermann 2002) are able to use exclusion. Thus, there need to be alternative explanations why these animals possess these cognitive skills. Therefore, caching as a key for exclusion could only be conceivable in corvids so far.

Acknowledgments The authors would like to thank the Herzog v. Cumberland Game Park and the 'Verein der Förderer' provided permanent support and the FWF (P20528-B17) for funding. Special thanks to Markus Boeckle, Thomas Bugnyar, Claudia Wascher, Vera Brust, Anna Braun and all members of the KLF for their support. We would like to thank the reviewers for their valuable comments on an earlier version of this manuscript. The conducted experiments comply with current Austrian law.

Conflict of interest The authors declare that they have no conflict of interest.

Open Access This article is distributed under the terms of the Creative Commons Attribution Noncommercial License which permits any noncommercial use, distribution, and reproduction in any medium, provided the original author(s) and source are credited.

\section{References}

Aust U, Range F, Steurer M, Huber L (2008) Inferential reasoning by exclusion in pigeons, dogs and humans. Anim Cogn 11(4):587-597. doi:10.1007/s10071-008-0149-0

Beran MJ, Washburn DA (2002) Chimpanzee responding during matching to sample: control by exclusion. J Exp Anal Behav 78:497-508

Bloom P (2004) Can a dog learn a word? Science 304:1605-1606

Bolhuis JJ, Macphail EM (2001) A critique of the neuroecology of learning and memory. Trends Cogn Sci 5:426-433

Bräuer J, Kaminski J, Riedel J, Call J, Tomasello M (2006) Making inference about the location of hidden food: social dog, causal ape. J Comp Psychol 120(1):38-47. doi:10.1037/0735-7036. 120.1.38

Bugnyar T, Kotrschal K (2002) Observational learning and the raiding of food caches in ravens, corvus corax: is it 'tactical' deception? Anim Behav 64:185-195

Call J (2004) Inferences about the location of food in the Great Apes (Pan paniscus, Pan troglodytes, Gorilla gorilla, and Pongo pygmaeus). J Comp Psychol 118(2):232-241. doi:10.1037/07357036.118 .2 .232

Call J (2006) Inference by exclusion in the great apes: the effect of age and species. Anim Cogn 9:393-403. doi:10.1007/s10071006-0037-4

Clement TS, Zentall TR (2003) Choice based on exclusion in pigeons. Psychon Bull Rev 10:959-964

de Kort SR, Clayton NS (2006) An evolutionary perspective on caching by corvids. Proc R Soc Ser B 273:417-423

Dixon LS (1977) The nature of control by spoken words over visual stimulus selection. J Exp Anal Behav 27(3):433-442

dos Anjos L, Debus S, Madge S, Marzluff J (2009) Corvidae. In: del Hoyo J, Elliott A, Christie DA (eds) Handbook of the birds of the world, vol. 14. Lynx Edicion, Barcelona

Emery NJ (2006) Cognitive ornithology: the evolution of avian intelligence. Philos Trans R Soc B 361:23-43 
Erdöhegyi A, Topal J, Viranyi Z, Miklosi A (2007) Dog-logic: inferential reasoning in a two-way choice task and its restricted use. Anim Behav 74:725-737. doi:10.1016/j.anbehav.2007.03. 004

Fischer J, Call J, Kaminski J (2004) A pluralistic account of word learning. Trends Cogn Sci 8(11):481

Goodwin D (1986) Crows of the world. British Museum of Natural History, London

Gould-Beierle K (2000) A comparison of four corvid species in a working and reference memory task using a radial maze. J Comp Psychol 114(4):347-356

Hackett SJ, Kimball RT, Reddy S, Bowie RCK, Braun EL, Braun MJ, Yuri T (2008) A pylogenomic study of birds reveals their evolutionary history. Science 320:1763-1767

Heinrich B (1989) Ravens in winter. Summit Books of Simon \& Schuster, New York

Hermann LM, Richards DG, Wolz JP (1984) Comprehension of sentences by bottlenose dolphins. Cognition 16:129-219

Itakura S, Agnetta B, Hare B, Tomasello M (1999) Chimpanzee use of human and conspecific social cues to locate hidden food. Dev Sci 2(4):448-456

Kamil AC (1987) A synthetic approach to the study of animal intelligence. Neb Symp Motiv 35:257-308

Kaminski J, Call J, Fischer J (2004) Word learning in a domestic dog: evidence for "fast mapping". Science 304:1682-1683. doi: 10.1126/science. 1097859

Kaminski J, Riedel J, Call J, Tomasello M (2005) Domestic goats, Capra hircus, follow gaze direction and use social cues in an object choice task. Anim Behav 69:11-18

Kastak CR, Schustermann RJ (2002) Sea lions and equivalence: expanding classes by exclusion. J Exp Anal Behav 78:449-465

Knoedler AJ (1999) The shift from recency to primacy with increasing delay. J Exp Psychol Learn Mem Cogn 25(2):474487

Krueger K, Flauger B, Farmer K, Maros K (2010) Horses (Equus caballus) use human local enhancement cues and adjust to human attention. Anim Cogn 14(2):187-201. doi:10.1007/ s10071-010-0352-7

Markman EM, Abelev M (2004) Word learning in dogs? Trends Cogn Sci 8(11):479-481

Markman EM, Wachtel GF (1988) Children's use of mutual exclusivity to constrain the meanings of words. Cogn Psychol 20(2):121-157

Paukner A, Anderson JR, Fujita K (2006) Redundant food searches by capuchin monkeys (Cebus apella): a failure of metacognition? Anim Cogn 9:110-117

Paukner A, Huntsberry ME, Suomi SJ (2009) Tufted capuchin monkeys (Cebus apella) spontaneously use visual but not acoustic information to find hidden food items. J Comp Psychol 123:26-33

Peignot P, Anderson JR (1999) Use of experimental given manual and facial cues by gorillas (Gorilla gorilla) in an object-choice task. J Comp Psychol 113:253-260

Pepperberg IM (2006) Ordinality and inferential abilities of a grey parrot (Psittacus erithacus). J Comp Psychol, 120(3). doi: 10.1037/0735-7036.120.3.205
Pepperberg IM (2007) Individual differences in grey parrots (Psittacus erithacus): effects of training. J Ornithol 148:161-168

Petit O, Call J, Thierry B (2005) Inference about food location in Tonkean macaques. Primate report 72:76

Pilley JW, Reid AK (2011) Border collie comprehends object names as verbal referents. Behav Process 86(2):184-195

Pineno O, Miller RR (2005) Primacy and recency effects in extinction and latent inhibition: a selective review with implications for models of learning. Behav Process 69:223-235

Russel J, Thompson D (2003) Memory development in the second year: for events or locations? Cognition 87:97-105

Sabbatini G, Visalberghi E (2008) Inferences about the location of food in Capuchin monkeys (Cebus apella) in two sensory modalities. Anim Behav 122(2):156-166. doi:10.1037/07357036.122 .2 .156

Schloegl C (2011) What you see is what you get-reloaded: can jackdaws (Corvus monedula) find hidden food through exclusion? J Comp Psychol 125(2):162-174. doi:10.1037/a0023045

Schloegl C, Kotrschal K, Bugnyar T (2008a) Do common ravens (Corvus corax) rely on human or conspecific gaze cues to detect hidden food. Anim Cogn 11:231-241

Schloegl C, Kotrschal K, Bugnyar T (2008b) Modifying the objectchoice task: is the way you look important for ravens? Behav Process 77(1):61-65

Schloegl C, Bugnyar T, Aust U (2009a) Exclusion performances in non-human animals: from pigeons to chimpanzees and back again. In: Blaisdell A, Huber L, Watanabe S, Young A, Yamazaki Y (eds) Rational animals, irrational humans. Keio University Press, Tokyo, pp 217-234

Schloegl C, Dierks A, Gajdon GK, Huber L, Kotrschal K, Bugnyar T (2009b) What you see is what you get? Exclusion performances in ravens and keas. Plos one 4(8):1-12. doi:10.1371/journal. pone. 0006368

Schmitt V, Fischer J (2009) Inferential reasoning and modality dependent discrimination learning in olive baboons (Papio hamadryas anubis). J Comp Psychol 123(3):316-325. doi: 10.1037/a0016218

Schustermann RJ, Krieger K (1984) California sea lions are capable of semantic comprehension. Psychol Rec 34:3-23

Tomonaga M (1993) Test for control by exclusion and negative stimulus relations of arbitrary matching to sample in a "symmetry-emergent" chimpanzee. J Exp Anal Behav 59:215-229

Tornick JK, Gibson BM, Kispert D, Wilkinson M (2010) Clark's nutcrackers (Nucifraga columbiana) use gestures to identify the location of hidden food. Anim Cogn 14(1):117-125. doi: 10.1007/s10071-010-0349-2

Viranyi Z, Gacsi M, Kubinyi E, Topal J, Belenyi B, Ujfalussy D, Miklosi A (2008) Comprehension of human-reared wolves (Canis lupus) and dogs (Canis familiaris). Anim Cogn 11:373-387

Wright AA, Santiago HC, Sands SF, Kendrick DF, Cook RG (1985) Memory processing of serial lists by pigeons, monkeys, and people. Science 229(4710):287-289

Zentall TR, Edwards CA, Moore BS, Hogan DE (1981) Identity: the basis for both matching and oddity learning in pigeons. J Exp Psychol Anim Behav Process 7(1):70-86 